\title{
Gene expression levels assessed by oligonucleotide microarray analysis and quantitative real-time RT-PCR - how well do they correlate?
}

\author{
Peter B Dallas*1, Nicholas G Gottardo*1, Martin J Firth², Alex H Beesley, \\ Katrin Hoffmann ${ }^{1}$, Philippa A Terry ${ }^{1}$, Joseph R Freitas ${ }^{1}$, Joanne M Boag${ }^{1}$, \\ Aaron J Cummings ${ }^{1}$ and Ursula R Kees ${ }^{1}$
}

\begin{abstract}
Address: ${ }^{1}$ Division of Children's Leukaemia and Cancer Research, Telethon Institute for Child Health Research and Centre for Child Health Research, The University of Western Australia, Perth, Australia and ${ }^{2}$ Division of Biostatistics and Genetic Epidemiology, Telethon Institute for Child Health Research and Centre for Child Health Research, The University of Western Australia, Perth, Australia

Email: Peter B Dallas* - peterd@ichr.uwa.edu.au; Nicholas G Gottardo* - nickg@ichr.uwa.edu.au; Martin J Firth - martyf@ichr.uwa.edu.au; Alex H Beesley - alex@ichr.uwa.edu.au; Katrin Hoffmann - katrinh@ichr.uwa.edu.au; Philippa A Terry - philippa@ichr.uwa.edu.au; Joseph R Freitas - josephf@ichr.uwa.edu.au; Joanne M Boag - joanneb@ichr.uwa.edu.au; Aaron J Cummings - aaroncummings1@optusnet.com.au; Ursula R Kees - ursula@ichr.uwa.edu.au

* Corresponding authors
\end{abstract}

Published: 27 April 2005

BMC Genomics 2005, 6:59 doi:10.1/86/147/-2164-6-59

This article is available from: http://www.biomedcentral.com/l47I-2164/6/59

(C) 2005 Dallas et al; licensee BioMed Central Ltd.

This is an Open Access article distributed under the terms of the Creative Commons Attribution License (http://creativecommons.org/licenses/by/2.0), which permits unrestricted use, distribution, and reproduction in any medium, provided the original work is properly cited.
Received: 06 October 2004

Accepted: 27 April 2005

\begin{abstract}
Background: The use of microarray technology to assess gene expression levels is now widespread in biology. The validation of microarray results using independent mRNA quantitation techniques remains a desirable element of any microarray experiment. To facilitate the comparison of microarray expression data between laboratories it is essential that validation methodologies be critically examined. We have assessed the correlation between expression scores obtained for 48 human genes using oligonucleotide microarrays and the expression levels for the same genes measured by quantitative real-time RT-PCR (qRT-PCR).

Results: Correlations with qRT-PCR data were obtained using microarray data that were processed using robust multi-array analysis (RMA) and the MAS 5.0 algorithm. Our results indicate that when identical transcripts are targeted by the two methods, correlations between qRT-PCR and microarray data are generally strong $(r=0.89)$. However, we observed poor correlations between QRT-PCR and RMA or MAS 5.0 normalized microarray data for $13 \%$ or $16 \%$ of genes, respectively.

Conclusion: These results highlight the complementarity of oligonucleotide microarray and qRTPCR technologies for validation of gene expression measurements, while emphasizing the continuing requirement for caution in interpreting gene expression data.
\end{abstract}

\section{Background}

The use of microarray technology to assess gene expression levels is now widespread in biology and, particularly in the clinical setting, the applicability of the methodology is likely to broaden as the technology evolves, data analysis procedures improve, and costs decline [1-3]. Two 
distinct microarray platforms, cDNA and oligonucleotide, are currently in general use [4]. While the relative merits of the two systems continue to be discussed [5], the validation of microarray results using independent mRNA quantitation techniques, including Northern blotting, ribonuclease protection, in situ hybridization, or quantitative real-time reverse transcription-polymerase chain reaction (qRT-PCR) remains a critical element of any microarray experiment $[6,7]$. Despite this, there have been few systematic validation studies of cDNA, or more noticeably, oligonucleotide microarray data using these independent approaches. For researchers to be confident with the interpretation of microarray results and for the establishment of consistent validation procedures in the microarray community for the purpose of data comparison, it is important that this issue be addressed.

We have undertaken an extensive series of experiments examining gene expression profiles in pediatric cancer specimens and normal tissues using oligonucleotide microarrays. For these studies, we used HG-U133A GeneChips (Affymetrix) which contain 22,283 probe sets representing approximately 14,500 human genes. To determine the preferred methodology for the analysis of our microarray data we compared the correlation between microarray expression scores obtained using two different data normalization procedures - Affymetrix MAS 5.0 [8], and robust multi-array analysis (RMA)[9] - with the expression levels obtained from follow-up verification experiments using qRT-PCR [10-12].

We found that the correlation between qRT-PCR and microarray expression data is generally strong. While our results highlight the complementarity of oligonucleotide microarray and qRT-PCR technologies for validation of gene expression measurements, the poor correlations that we observed for $13-16 \%$ of genes emphasizes the importance and continuing requirement for caution in interpreting gene expression data.

\section{Results}

We have assessed the degree of correlation between microarray expression scores obtained for 48 genes using HGU133A GeneChips with expression levels measured for the same genes using qRT-PCR. The genes that we assessed were identified as part of a larger study underway in the laboratory examining differential gene expression in pediatric leukemias and brain tumor specimens. The 48 genes were targeted for validation either on the basis of their differential expression between our subsets of interest (e.g. brain tumour vs normal brain specimens, leukemia specimens vs normal CD34+ stem cells) as determined by microarray analysis, or because they mapped to chromosomal regions of interest. In those cases where there were multiple microarray probe sets for particular genes, only data from those that showed evidence of differential expression were chosen for validation. For genes that were selected from chromosomal regions of interest and not necessarily on the basis of differential expression, correlations were carried out using data from the probe set deemed most specific for the gene of interest by the Affymetrix software (e.g. microarray probe sets designated - at are considered more specific than -s-at and $-x$-at probe sets).

In total, 889 specimen/gene combinations were assayed by qRT-PCR and microarray in this study. Overall, statistically significant correlations $(p<0.05)$ were observed between qRT-PCR and RMA normalized data for 33/48 (69\%) genes, and between qRT-PCR and MAS 5.0 normalized data for 32/48 (67\%) genes (Tables 1 and 2, genes in bold). Typical data for a gene with a good correlation is presented in Figure 1. The correlation between the qRTPCR data and microarray data normalized using either of the two methods was not significant ( $\mathrm{p}>0.05$ ) for $14 / 48$ (29\%) genes (Tables 1 and 2 , genes non-bold). Two genes, FLJ20003 and RB, showed significant correlations by RMA but not by MAS 5.0 analysis, while one gene, GCLC, had a significant correlation by MAS 5.0 but not by RMA.

By careful analysis of the relevant databases (see Methods) we identified a subset of 31 genes for which the microarray probe-sets were deemed to recognize the exact same transcript or subset of transcripts as the qRT-PCR probes (Table 1). When we assessed the levels of correlation for this group of 31 transcript-concordant genes a higher proportion of significantly correlating scores was observed; $84 \%$ (26/31) for MAS 5.0 normalized data and 87\% (27/ 31) for RMA normalized data (Table 1, genes in bold). In addition, the average correlations between the MAS 5.0 or RMA data and the qRT-PCR data for this subset of genes were very similar ( 0.71 and 0.72 , respectively). In contrast, for the remaining 17 genes for which the Affymetrix microarray probe-sets may not recognize the same subset of transcript(s) recognized by qRT-PCR probes, significant correlations were observed for only $41 \%(7 / 17)$ genes by either MAS 5.0 and RMA (Table 2). All genes with poor correlations were tested on the same numbers of samples as those genes that did correlate, and there was no relationship between sample type and whether or not correlation was significant. Separate genes were targeted for each sample type. Using a two sample t-test, the average correlations between RMA-qRT-PCR scores and MAS-qRT-PCR scores for the transcript concordant genes in Table 1 were significantly higher than the average of the equivalent correlations for the non-concordant genes in Table 2 (RMAqRT-PCR Table 1 vs 2, $\mathrm{p}=0.0005$; MAS-qRT-PCR Table 1 vs $2, \mathrm{p}=0.0003$ ). 
Table I: A comparison of average qRT-PCR, RMA, and MAS 5.0 scores and the corresponding correlation values for the 3 I transcriptconcordant genes assayed in this study for which the Affymetrix microarray probesets (Affy IDs) were deemed likely to recognize identical transcripts to qRT-PCR probes. Genes are ranked from lowest to highest average $\log _{2}$ RMA scores. Genes with significant correlations $(p<0.05)$ obtained by either normalization procedure are highlighted in bold. The number of specimens tested for each gene is included $(n)$. Expression levels are shown as $\log _{2}>$.

\begin{tabular}{|c|c|c|c|c|c|c|c|}
\hline \multicolumn{2}{|c|}{ GENE } & \multirow[b]{2}{*}{$\mathbf{n}$} & \multicolumn{3}{|c|}{ EXPRESSION } & \multicolumn{2}{|c|}{ CORRELATION } \\
\hline NAME & AFFY ID & & RMA & MAS 5.0 & qRT-PCR & $\begin{array}{c}\text { RMA-qRT- } \\
\text { PCR }\end{array}$ & $\begin{array}{l}\text { MAS-qRT- } \\
\text { PCR }\end{array}$ \\
\hline LCE & 204256_at & 22 & 4.79 & 7.01 & 0.27 & 0.81 & 0.70 \\
\hline ALDHIAI & 212224_at & 22 & 4.93 & 6.66 & -2.93 & 0.89 & 0.88 \\
\hline CFLAR & 211317_s_at & 13 & 5.61 & 7.92 & -0.12 & 0.65 & 0.75 \\
\hline REL & 206036_s_at & 13 & 5.63 & 8.36 & 0.53 & 0.76 & 0.77 \\
\hline$A B C C 4$ & 203196_at & 22 & 5.84 & 7.54 & 0.09 & 0.78 & 0.89 \\
\hline FOXOIA & 202724_s_at & 19 & 5.91 & 7.43 & -2.05 & 0.85 & 0.90 \\
\hline NOTCH2 & 212377_s_at & 13 & 6.19 & 8.24 & -0.43 & 0.77 & 0.82 \\
\hline TNFRSF2I & 214581_x_at & 13 & 6.22 & 8.03 & 1.98 & 0.83 & 0.97 \\
\hline MADH9 & 206320_s_at & 19 & 6.24 & 5.47 & -2.29 & 0.87 & 0.74 \\
\hline PPMID & 204566_at & 30 & 6.29 & 8.80 & 0.50 & 0.73 & 0.72 \\
\hline MAP7 & 202889_x_at & 22 & 6.42 & 6.27 & -3.51 & 0.85 & 0.87 \\
\hline$D M B T I$ & 208250_s_at & 19 & 6.49 & 7.25 & -6.49 & 0.20 & -0.11 \\
\hline SNIPI & 219409_at & 13 & 6.57 & 8.34 & 1.08 & 0.69 & 0.77 \\
\hline OSF2 & 210809_s_at & 19 & 6.59 & 7.68 & -1.26 & 0.80 & 0.77 \\
\hline ATBFI & 208033_s_at & 19 & 6.64 & 7.14 & 0.27 & 0.81 & 0.84 \\
\hline$K I T$ & 20505I_s_at & 22 & 6.70 & 7.51 & -2.73 & 0.86 & 0.87 \\
\hline P53 & 201746_at & 19 & 7.00 & 8.50 & -3.44 & 0.41 & 0.11 \\
\hline BAG3 & 21791I_s_at & 19 & 7.04 & 8.61 & -0.98 & 0.79 & 0.82 \\
\hline$R B$ & 203132_at & 19 & 7.04 & 9.14 & -2.82 & 0.45 & 0.38 \\
\hline WBP4 & 203599_s_at & 19 & 7.28 & 8.97 & -0.24 & 0.62 & 0.74 \\
\hline BNIP2 & 209308_s_at & 13 & 7.58 & 9.79 & 0.56 & 0.68 & 0.69 \\
\hline UMPCMPK & 217870_s_at & 13 & 8.17 & 10.98 & 1.10 & 0.37 & 0.12 \\
\hline DCAMKLI & 205399_at & 19 & 8.18 & 9.23 & -3.57 & 0.76 & 0.89 \\
\hline OAZIN & 201772_at & 30 & 8.22 & 10.36 & -0.36 & 0.72 & 0.77 \\
\hline LHFP & 218656_s_at & 19 & 8.37 & 9.27 & -0.46 & 0.89 & 0.90 \\
\hline BTG3 & 205548_s_at & 13 & 8.47 & 10.54 & 0.83 & 0.86 & 0.90 \\
\hline$D C X$ & 204850_s_at & 19 & 8.81 & 10.08 & 0.62 & 0.87 & 0.88 \\
\hline TERF2 & 2036II_at & 19 & 9.05 & 10.04 & -0.14 & 0.32 & 0.31 \\
\hline GADD45A & 203725_at & 19 & 9.17 & 9.80 & -0.12 & 0.96 & 0.94 \\
\hline PRSSII & 201185_at & 19 & 9.22 & 9.85 & -3.54 & 0.63 & 0.64 \\
\hline RAPI & 201174_s_at & 19 & 10.34 & 11.59 & -0.82 & 0.83 & 0.84 \\
\hline
\end{tabular}

Determining fold-changes in gene expression levels between subsets of interest is often a major aim of microarray studies. To address this issue, we analyzed foldchange in average gene expression levels between our subsets of interest (e. g. tumor vs normal) by both qRT-PCR and RMA or MAS 5.0 microarray scores for the same genes. Only the 31 transcript-concordant genes were considered in this analysis (Table 1). From a total of $587 \mathrm{spec}-$ imen/gene combinations we found a significant and strong correlation in mean fold-change using both RMA ( $\mathrm{r}$ $=0.89, \mathrm{p}<0.05)$ and MAS $5.0(\mathrm{r}=0.92, \mathrm{p}<0.05)$ (Figure $2 \mathrm{a}, \mathrm{b})$. Interestingly, we noticed a trend towards poorer correlation for genes that exhibited fold-change differences of $<1.5$ between subsets of interest based on micro- array expression scores compared to those with foldchange differences of $>1.5$ (data not shown). The slopes of the two regression lines in Fig. 2 are significantly greater than one [RMA vs qRT-PCR $=1.49(95 \% \mathrm{CI}=1.20,1.77)$; MAS vs qRT-PCR $=1.23(95 \% \mathrm{CI}=1.03,1.42)]$.

\section{Discussion}

Microarray expression analysis has revolutionized many facets of biology and will continue to be applied widely. However, significant questions remain with regard to the generation, analysis, and in particular, interpretation of microarray data. Although the validation of microarray expression results obtained for specific genes using independent techniques is still considered a desirable 
Table 2: A comparison of average qRT-PCR, RMA, and MAS 5.0 scores and the corresponding correlation values for the 17 genes assayed in this study for which the Affymetrix microarray probesets (Affy IDs) may not recognize the exact same transcript subsets recognized by qRT-PCR probes. Genes are ranked from lowest to highest average $\log _{2}$ RMA scores. Genes with significant correlations $(p<0.05)$ obtained by either normalization procedure are highlighted in bold. The number of specimens tested for each gene is included (n). Expression levels are shown as $\log _{2}$.

\begin{tabular}{|c|c|c|c|c|c|c|c|}
\hline \multicolumn{2}{|c|}{ GENE } & \multirow[b]{2}{*}{$\mathbf{n}$} & \multicolumn{3}{|c|}{ EXPRESSION } & \multicolumn{2}{|c|}{ CORRELATION } \\
\hline NAME & AFFY ID & & RMA & MAS 5.0 & qRT-PCR & $\begin{array}{c}\text { RMA-qRT- } \\
\text { PCR }\end{array}$ & $\begin{array}{l}\text { MAS-qRT- } \\
\text { PCR }\end{array}$ \\
\hline$C D C / 4 A$ & 210742_at & 13 & 5.77 & 7.64 & -0.67 & 0.31 & 0.26 \\
\hline$P / 25$ & 209175_at & 19 & 6.61 & 8.43 & 0.54 & 0.11 & -0.11 \\
\hline GCLC & 202922_at & 13 & 6.65 & 9.20 & 0.33 & 0.46 & 0.56 \\
\hline MAP3K7 & 206853_s_at & 13 & 6.65 & 8.72 & 1.19 & 0.11 & -0.10 \\
\hline TIALI & 202405_at & 19 & 6.68 & 7.86 & 0.30 & 0.32 & 0.17 \\
\hline FLJ20003 & 219067_s_at & 19 & 6.71 & 8.54 & 0.64 & 0.64 & 0.34 \\
\hline RUNXI & 210365_at & 13 & 6.95 & 9.24 & 1.47 & 0.29 & 0.28 \\
\hline PLEKHAI & 219024_at & 19 & 6.99 & 8.18 & -2.88 & -0.40 & -0.28 \\
\hline FLJI 2661 & 218420_s_at & 19 & 7.35 & 8.50 & 0.57 & -0.08 & -0.17 \\
\hline RGC32 & 218723_s_at & 19 & 7.36 & 8.11 & -3.20 & 0.85 & 0.96 \\
\hline WDRII & 218090_s_at & 19 & 7.96 & 9.04 & 0.60 & 0.12 & 0.01 \\
\hline RFC3 & 204127_at & 19 & 8.10 & 9.77 & 1.20 & 0.62 & 0.64 \\
\hline ASAHI & 213702_x_at & 22 & 8.30 & 10.29 & 1.46 & 0.29 & 0.27 \\
\hline P38IP & 220408_x_at & 19 & 8.35 & 9.55 & 0.76 & 0.73 & 0.65 \\
\hline BUB3 & 201456_s_at & 19 & 8.41 & 9.70 & 0.60 & 0.64 & 0.61 \\
\hline SAC2 & 203607_at & 19 & 8.86 & 10.21 & 0.35 & 0.22 & 0.12 \\
\hline TSC22 & 2151II_s_at & 19 & 10.56 & 11.87 & -1.34 & 0.83 & 0.82 \\
\hline
\end{tabular}

component of any microarray experiment, the genes selected for validation $a$ priori, are usually identified from the microarray data. The selection is based on the implicit assumption that there is a good correlation between the microarray data and actual mRNA levels in the cells under investigation. One fundamental issue that has not been adequately addressed is how well microarray expression scores reflect actual mRNA levels in the sample being examined.

To facilitate data comparison between research groups it is important that the microarray community moves to adopt consistent validation methodologies. This is especially important if microarray technology is to play a role in the clinical setting [13]. However, the choice of validation methodology remains a contentious issue [14]. To date, qRT-PCR is the method of validation that has been used in the majority of published microarray studies, presumably because it is a rapid, sensitive, high throughput procedure that requires minimal amounts of test material compared to techniques such as Northern blotting or ribonuclease protection assays. As is the case for many studies, including ours, qRT-PCR is often the only feasible approach when rare or unique tissues are investigated. For these reasons, it would appear likely that qRT-PCR will continue to be used extensively for the validation of microarray expression data [15]. To our knowledge, this study is the most extensive and practical examination of mammalian cells that focuses on the degree of correlation between expression level measurements obtained by oligonucleotide microarray analysis and qRT-PCR.

We observed strong correlations $(\mathrm{p}<0.05)$ for the majority $(>87 \%)$ of the 31 transcript-concordant genes that we examined in this study. In addition, although the MAS 5.0 software and RMA use different algorithms for the normalization of microarray data $[8,9]$ we found that the degree of correlation between microarray and qRT-PCR results was very similar irrespective of the normalization procedure employed.

Our data clearly demonstrate that similar microarray scores for different genes do not necessarily mean that similar qRT-PCR scores will be obtained. For example, ATBF1, OSF2, and SNIP1 yielded similar average $\log _{2}$ RMA scores ( 6.6) but the average $\log _{2}$ qRT-PCR scores for the same genes were substantially different $(0.27,-1.26$, and 1.08, respectively). Similarly, KIT and ABCC4 exhibited identical average $\log _{2}$ MAS 5.0 scores ( 7.5), while the corresponding average $\log _{2}$ qRT-PCR scores were -2.73 and 0.09 , respectively. The finding that genes with similar microarray expression scores were unlikely to have similar qRT-PCR results presumably reflects the different hybridization kinetics of the probe sets for each gene. This 


\section{A}

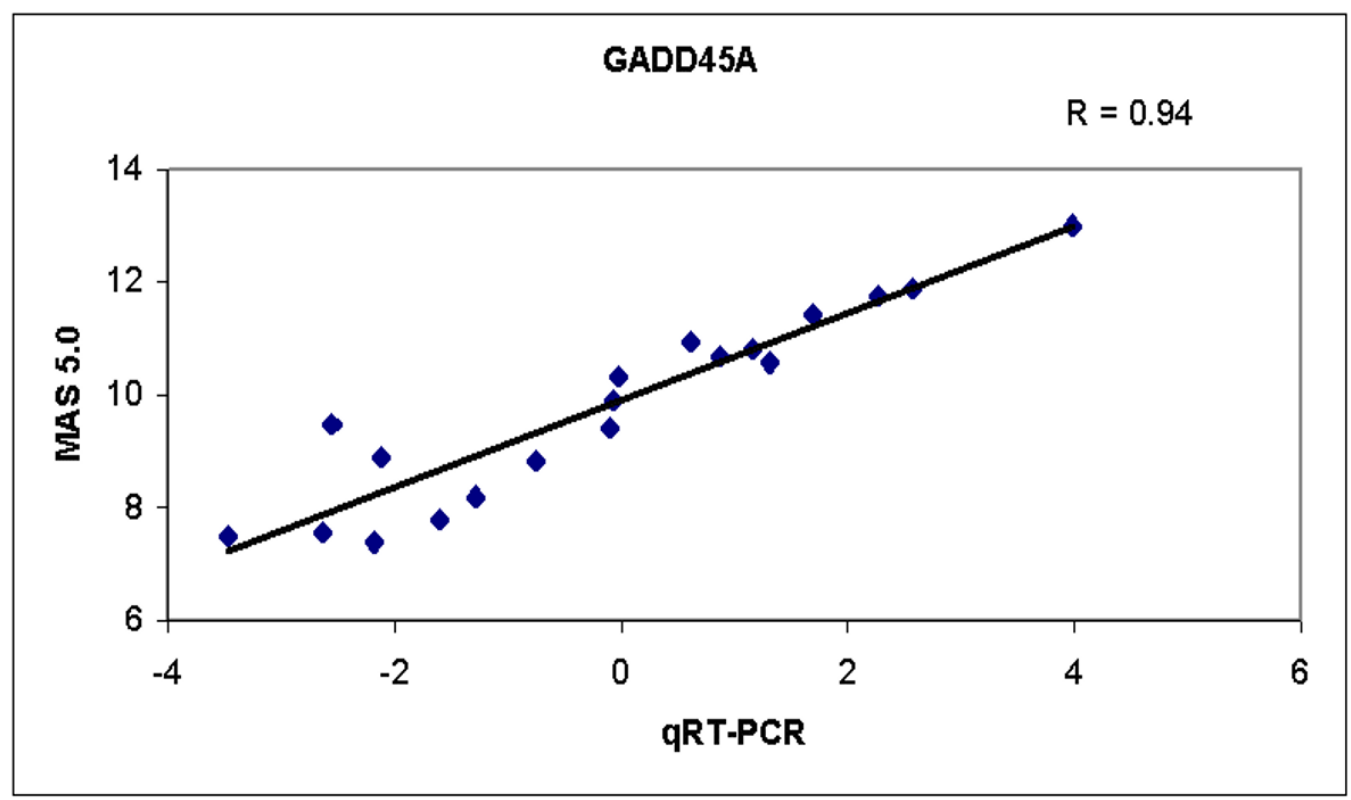

B

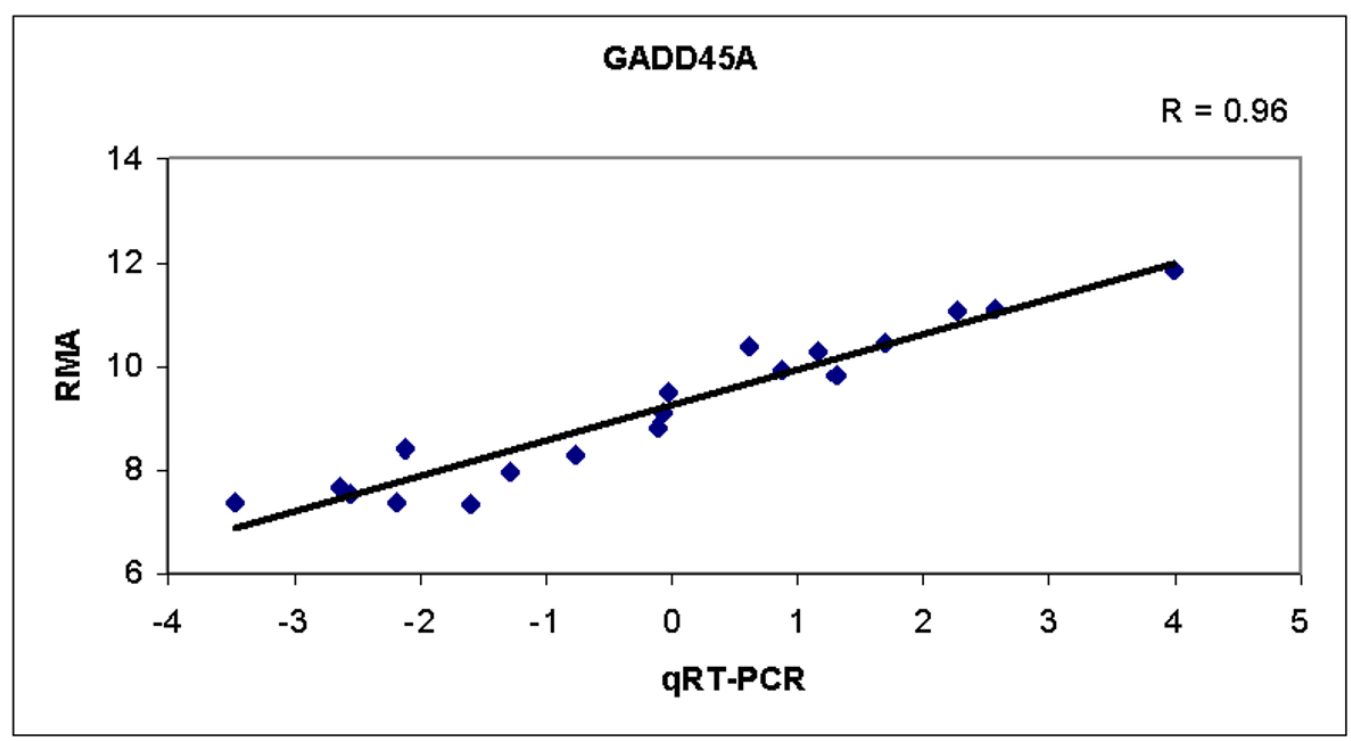

Figure I

Examples of Pearson's correlations between gene expression levels determined by qRT-PCR and oligonucleotide microarray for one gene assessed in this study. The mRNA levels for the gene GADD45A were determined by qRT-PCR and correlated with microarray expression scores determined after data processing using MAS 5.0 software (A) or RMA (B). All data are shown as $\log _{2}$. 
A

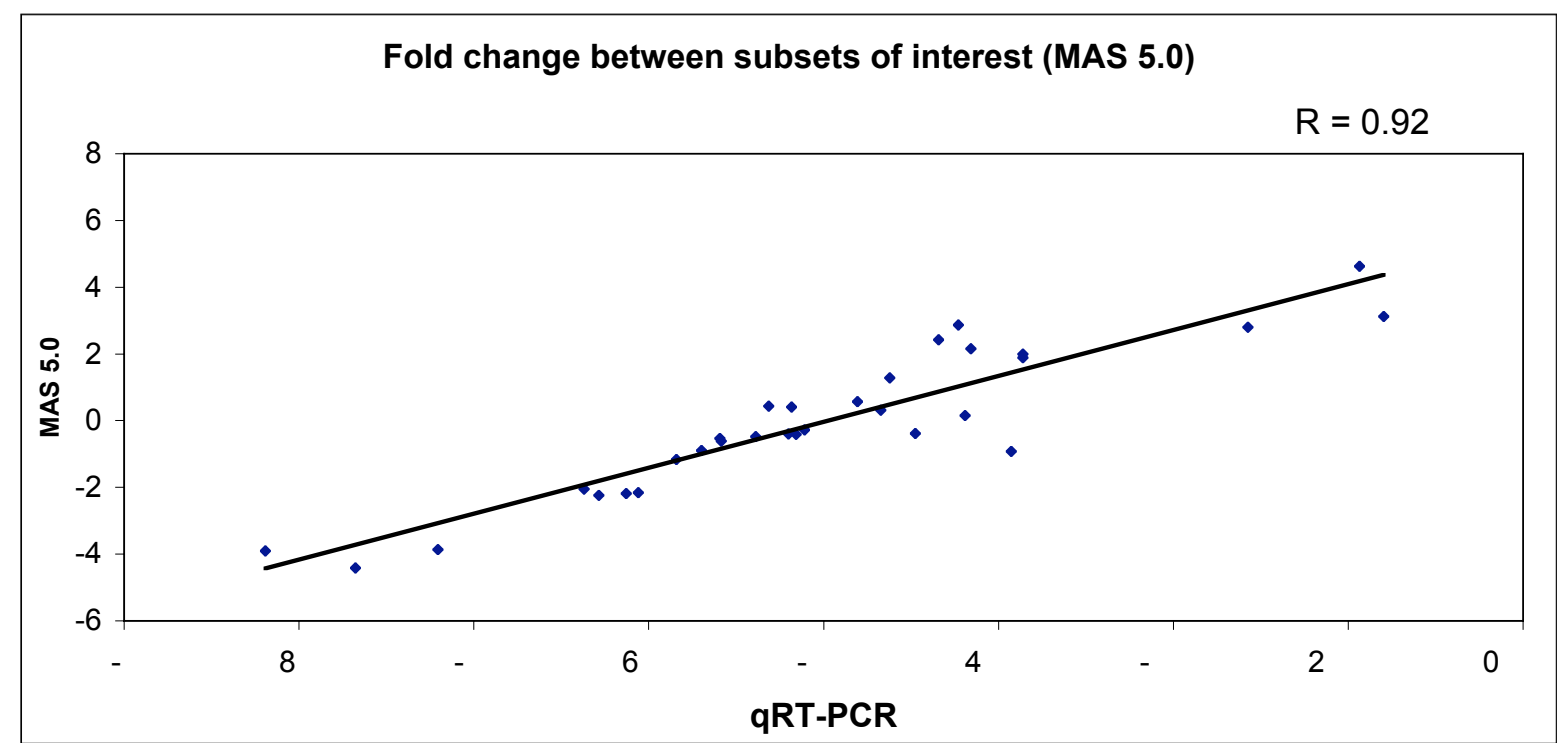

B

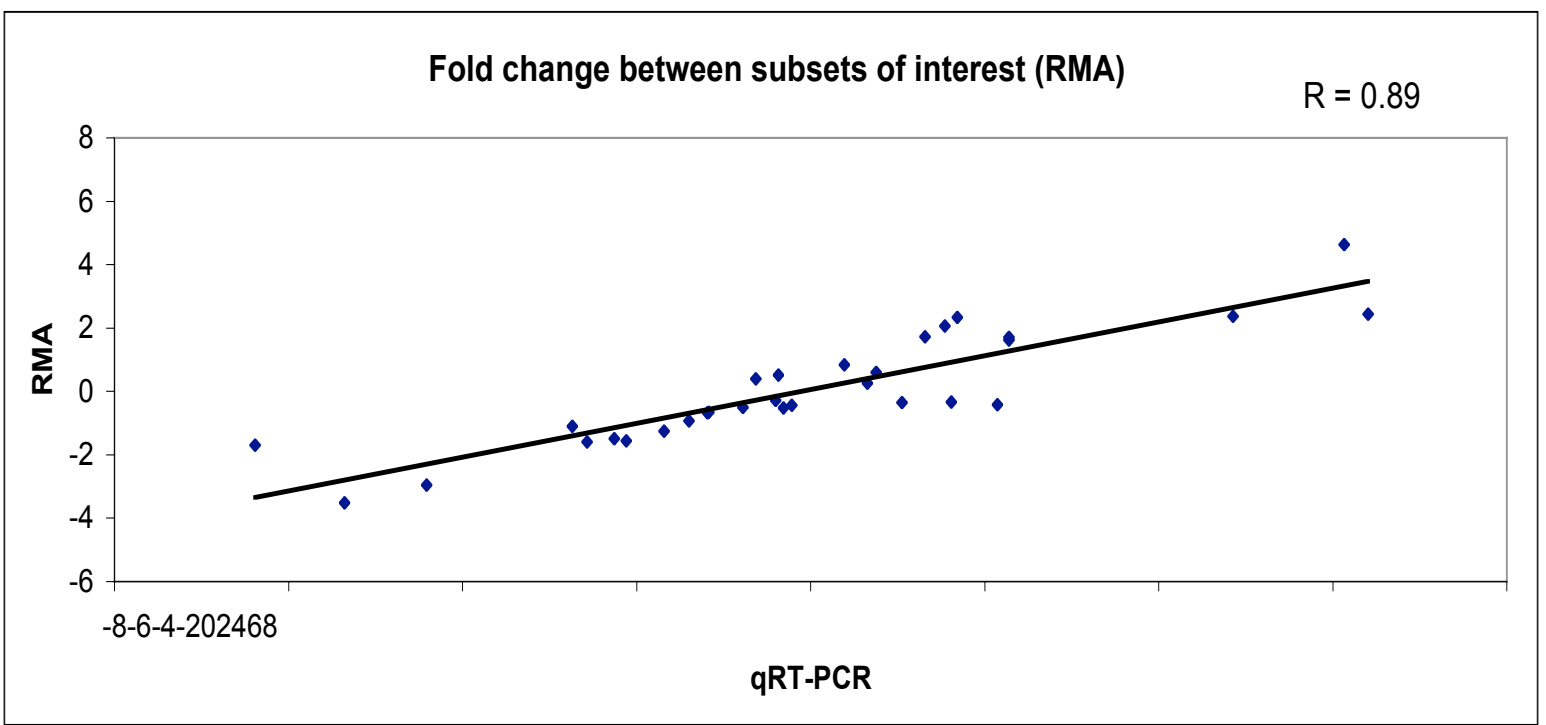

Figure 2

Pearson's correlations between fold-change in average gene expression levels between subsets of interest assessed by qRTPCR and either MAS 5.0 software (A) or RMA (B) for the $3 \mathrm{I}$ transcript-concordant genes (see Table I). All data are shown as $\log _{2}$. 
observation has the major implication that on the basis of the qRT-PCR data that we obtained, it is generally not feasible to predict the true expression level of one gene based on the microarray expression score of another. In addition, we observed significant correlations for many genes with microarray expression scores, at least by RMA, of less than $100\left(\sim \log _{2} 100=6.64\right)$, which is at the lower end of the range of microarray scores we obtained in this study (range 6-23000). This finding indicates that the exclusion of genes with low microarray expression scores (e.g. <100) from further analysis, as has been adopted by some research groups in early microarray studies, may not be justified.

Determining fold-changes in gene expression levels between subsets of interest is often a critical aim of microarray studies. We found a significant and strong correlation using RMA $(\mathrm{r}=0.89, \mathrm{p}<0.05)$ and MAS $5.0(\mathrm{r}=0.92$, $\mathrm{p}<0.05$ ). These data indicate that the direction of change of gene expression levels (i.e. either up or down regulation) between subsets of interest is accurately predicted by comparison of average microarray expression scores. Again, the fold-change correlations we observed were very similar irrespective of the normalization procedure we employed. Consistent with the results of Yuen et al (2001)[16], fold change results determined by qRT-PCR were significantly greater than fold change assessed for the same genes by microarray analysis.

A recent study addressing gene expression profiles in Arabidopsis reported a good correlation between oligonucleotide microarray and SYBR green qRT-PCR data when ratios of gene expression in shoot tissue versus root tissue were compared for highly expressed genes. However, the correlations between shoot versus root ratios were generally poor for genes expressed at low levels [17]. We observed a similar trend towards poorer correlation for genes that exhibited fold-change differences of $<1.5$ between subsets of interest based on microarray expression scores compared to those with fold-change differences of $>1.5$. It is likely that this trend relates to the fact that small variations in mRNA levels $(<2$-fold) can be accurately detected by qRT-PCR, while the smaller dynamic range of microarrays means that the same changes may not be accurately reflected by microarray expression scores, especially for genes expressed at low levels ( $<1.5 \mathrm{pM}$ or approximately 3.5 copies/cell) $[18,19]$. This latter point is a likely explanation for the poor correlation observed for one gene, DMBT1, which is expressed at very low levels according to our qRT-PCR data. Etienne et al., 2004 [20] observed a lower overall correlation between microarrray and semi-quantitative RT-PCR data compared to our study. These authors hypothesized that in addition to genes with low expression levels, those with very high expression levels or a greater percentage of absent calls, may show lower levels of correlation between Affymetrix expression scores and semi-quantitative RTPCR data. We considered these issues in relation to the other poorly correlating genes in our study and found that none were expressed at levels that approach the fluorescence ceiling for the Affymetrix scanner ( 50000). In addition, the absolute number or percentage of absent calls did not correlate significantly $(\mathrm{p}>0.05)$ with the level of correlation between qRT-PCR results and microarray data (data not shown). It is possible that the differences between our results and those of Etienne and coworkers are related to the particular semi-quantitative RTPCR methodology employed by these researchers, which may not be as sensitive as qRT-PCR, and as the authors point out, may not detect certain low level transcripts.

In addition to DMBT1 mentioned above, we identified 13 other poorly correlating genes from the 48 genes we assessed. Careful analysis of the alternative transcript data available through the LocusLink database http:// www.ncbi.nih.nlm/LocusLink indicated that for 10 of these 13 genes, different subsets of alternative transcripts may be recognized by microarray probe sets and qRT-PCR probes. Hence, this may be the explanation for the poor correlations observed for these genes. Possible explanations for the poor correlations that were observed for the three remaining genes ( $p 53, U M P C M P K$, and TERF2), all of which were transcript-concordant, include the existence of alternative cross-hybridising transcripts differentially recognized by the oligonucleotide probe sets and qRT-PCR probes, gene specific variation related to the different hybridization kinetics associated with the two technologies, and misleading results associated with errors in GenBank sequence data and/or probe set annotations [21]. Additional experimental data will be required to address these possibilities. It is important to note that in our hands the reproducibility of both the qRT-PCR and oligonucleotide microarray methods is very high $[22,23]$. Hence, it is unlikely that poor correlations observed in our study are associated with issues of experimental precision.

Interestingly, the microarray and qRT-PCR expression data correlated well for five genes for which the microarray probe sets were deemed unlikely to recognize the same transcripts as the qRT-PCR probes. These data suggest that despite the possibility of differential transcript recognition, identical transcripts were being detected by both assays in the particular tissues involved.

\section{Conclusion}

Our data indicate that correlations between qRT-PCR and microarray data are generally strong; a result that is particularly encouraging for those researchers with access to only very limited amounts of rare or unique test specimens. Our data also emphasize the importance of ensur- 
ing that qRT-PCR probes recognize the same transcript(s) as the microarray probe set. Finally, the $13-16 \%$ non-concordance that we observed indicates that independent validation of expression data continues to be an important consideration.

\section{Methods}

Specimens

Informed consent for the use of tissues for research purposes was obtained for all individuals involved in this study according to hospital and Australian National Health and Medical Research (NHMRC) guidelines.

We extracted total RNA from 64 specimens, including 13 primary pediatric brain tumors, six pediatric brain tumor cell lines, two normal adult brain cortices, and one fetal brain germinal matrix. We also obtained total RNA from fetal brain pooled from multiple individuals (Clontech). In addition, total RNA was extracted from 36 pediatric acute lymphoblastic leukemia bone marrow specimens and from $\mathrm{CD}_{3} 4^{+}$hematopoietic stem cells isolated from the bone marrows of 5 normal individuals. Ficollhypaque purified leukemia cells or cryopreserved bone marrow specimens were snap frozen and stored in liquid nitrogen until required. Total RNA was extracted from $\sim 1$ $\times 10^{6}-2 \times 10^{7}$ live cells. Primary brain tumour specimens (10 - $150 \mathrm{mg})$ were either wrapped in foil or placed in RNAlater (Ambion) immediately after resection and stored at $-80^{\circ} \mathrm{C}$. Brain tumour cell lines were processed directly from tissue culture.

\section{RNA extraction, preparation of target cRNA and hybridization to HG-UI33A GeneChips}

Total RNA was extracted from all specimens using a combination of TRIZOL reagent (Invitrogen), RNeasy Mini kit (Qiagen) and ethanol precipitation. Following the TRIZOL reagent procedure, 0.53 volumes of $100 \%$ ethanol were added drop-wise to the aqueous phase and the mixture applied to RNeasy mini columns according to the manufacturer's instructions. Further purification and concentration was achieved through an additional ethanol precipitation. The integrity of the RNA preparation was assessed using agarose gel electrophoresis and analysis on an Agilent 2100 Bioanalyzer (Agilent Technologies). Biotinylated cRNAs for hybridization were prepared from total RNA according to Affymetrix protocols. Agarose gel electrophoresis was used to confirm the integrity of labelled cRNA and to assess its fragmentation products. Biotinylated cRNA preparations $(15 \mu \mathrm{g})$ were hybridized to HG-U133A arrays, which were subsequently washed, stained, and scanned using a GeneArray Scanner (Agilent Technologies) according to the Affymetrix protocol.

\section{Processing and statistical analysis of microarray data}

Array images were reduced to intensity values for each probe (cel files) using Affymetrix MAS 5.0 software and only those microarrays meeting acceptable Affymetrix quality control criteria were considered for further analysis. Cel files were then processed using either the MAS 5.0 software [8] or RMA (Bioconductor release 1.2) [9], an alternative algorithm that is publicly available at http://www.bioconductor.org. The MAS 5.0 algorithm uses a scalar normalization technique taking into account perfect match (PM) and mismatch (MM) probe pairs to correct for non-specific hybridization, while RMA is based on a quantile normalization approach which ignores $\mathrm{MM}$ values. All microarrays processed using the MAS 5.0 software were scaled to a standard target intensity of 500. For comparison purposes, all microarray and qRT-PCR data are presented as $\log _{2}$ and absent/present calls generated by the MAS 5.0 software were not taken into account.

Pearson's correlations were used for the comparison of qRT-PCR and microarray data and p-values were obtained using Fisher's z-transformation. Correlations were considered significant at $\mathrm{p}<0.05$.

\section{Bioinformatics}

To determine whether transcripts recognized by microarray probe sets [24] were likely to be identical to those detected by qRT-PCR probes, alternative splicing patterns for each gene were thoroughly reviewed using LocusLink http://www.ncbi.nlm.nih.gov and Ensembl http:// www.ensembl.org. Any full-length human mRNA or cDNA sequences demonstrating alternative splicing, in addition to NCBI-reviewed Reference Sequences (RefSeq), were considered as potential isoforms for each gene. Using BLAST alignments http://www.ncbi.nlm.nih.gov of probe and cDNA sequences, the members of each isoform 'family' that could be targeted by either qRT-PCR or microarray were identified (typically multiple isoforms for each gene). The potential number of isoforms recognised by each technology were then compared. Probes which targeted exactly the same isoform subsets for each gene were considered 'transcript-concordant' and placed in Table 1; those for which at least one of the targeted isoforms differed (regardless of the number of matching isoforms) were considered 'non transcript-concordant' and placed into Table 2 .

\section{QRT-PCR}

All qRT-PCR assays were carried out using primer and probe sets from Applied Biosystems (ABI Assays on Demand, http://www.appliedbiosystems.com/). Each assay was designed using ABI's primer/probe selection algorithm and bionformatics pipeline which includes access to both public and Celera DNA sequence databases. 
The combination of gene specific primers and a gene specific probe ensures a high degree of specificity.

Aliquots of total RNA extracted for microarray analysis as described above were used for qRT-PCR experiments according to the manufacturer's protocols (ABI). All ABI Assays on Demand are designed to generate amplicons of $50-150$ bp and are carried out using identical cycling conditions. 1-2 ug total RNA (quantitated by spectrophotometer at $\mathrm{OD}_{260}$ ) was used for each RT reaction. Three RT reactions were pooled and all qRT-PCR reactions were carried out using aliquots from the pool. We did not detect DNA contamination in any of our total RNA preparations after qualitative assessment using an Agilent Bioanalyzer. All qRT-PCR assays for a particular gene were undertaken at the same time under identical conditions and carried out in duplicate. All qRT-PCR experiments were run on an ABI 7700 sequence detector.

For all qRT-PCR assays the expression levels of target genes were normalised to the levels of the ACTB housekeeping gene utilising a standard curve method for quantitation as described previously [25]. Serial dilutions of cDNAs generated from selected cell lines that expressed target genes at a suitable level were used to generate a standard curve for each target gene and ACTB. The standard curves were then used to determine expression values (expressed as ng cDNA template) for each target gene after qRT-PCR analysis of each test specimen. Relative expression values for each target gene were expressed as a ratio of target gene expression level to ACTB expression level in the same specimen. These ratios were then correlated with the microarray data.

\section{Authors' contributions}

PBD and NGG contributed equally to this work and were responsible for designing the study, analysing, collating, and interpreting the data, and preparing the manuscript. MJF carried out the statistical analysis, $\mathrm{AHB}$ and $\mathrm{KF}$ assisted with data analysis, experimental design, and data interpretation. PAT, JRF, JMB, AJC and NGG carried out the microarray and qRT-PCR experiments. URK supervised all aspects of the study and preparation of the manuscript.

\section{Acknowledgements}

This study was supported by funds from NHMRC project grants 254595 and 254596, NCI/NIH grant 95475, the Three Boys Legacy, and Variety Club of Western Australia. We would like to thank Nigel Swanson and Violet Peeva at the Lotterywest State MicroArray Facility, Perth, Western Australia. Thanks also to Reinete Orr for secretarial assistance. NGG was supported by a National Childhood Cancer Foundation Laura and Greg Norman Fellowship.

\section{References}

I. Howbrook DN, van der Valk AM, O'Shaughnessy MC, Sarker DK, Baker SC, Lloyd AW: Developments in microarray technologies. Drug Discov Today 2003, 8:642-65I.

2. Jordan B: Historical background and anticipated developments. Ann N Y Acad Sci 2002, 975:24-32.

3. Russo G, Zegar C, Giordano A: Advantages and limitations of microarray technology in human cancer. Oncogene 2003, 22:6497-6507.

4. Kees UR: Gene expression signatures in lymphoid tumours. Immunol Cell Biol 2004, 82:I54-I60.

5. Moreau Y, Aerts S, De Moor B, De Strooper B, Dabrowski M: Comparison and meta-analysis of microarray data: from the bench to the computer desk. Trends Genet 2003, 19:570-577.

6. Chuaqui RF, Bonner RF, Best CJ, Gillespie JW, Flaig MJ, Hewitt SM, Phillips JL, Krizman DB, Tangrea MA, Ahram M, Linehan WM, Knezevic V, Emmert-Buck MR: Post-analysis follow-up and validation of microarray experiments. Nat Genet 2002, 32:509-5I4.

7. Brazma A, Hingamp P, Quackenbush J, Sherlock G, Spellman P, Stoeckert C, Aach J, Ansorge W, Ball CA, Causton HC, Gaasterland T, Glenisson P, Holstege FC, Kim IF, Markowitz V, Matese JC, Parkinson H, Robinson A, Sarkans U, Schulze-Kremer S, Stewart J, Taylor R, Vilo J, Vingron M: Minimum information about a microarray experiment (MIAME)-toward standards for microarray data. Nat Genet 200I, 29:365-37I.

8. Affymetrix technical note: Statistical algorithms guide. [http:// www.affymetrix.com/support/technical/technotesmain.affx].

9. Irizarry RA, Hobbs B, Collin F, Beazer-Barclay YD, Antonellis KJ, Scherf U, Speed TP: Exploration, normalization, and summaries of high density oligonucleotide array probe level data. Biostatistics 2003, 4:249-264.

10. Heid CA, Stevens J, Livak KJ, Williams PM: Real time quantitative PCR. Genome Res 1996, 6:986-994.

I I. Livak KJ, Flood SJ, Marmaro J, Giusti W, Deetz K: Oligonucleotides with fluorescent dyes at opposite ends provide a quenched probe system useful for detecting PCR product and nucleic acid hybridization. PCR Methods Appl 1995, 4:357-362.

12. Mocellin S, Rossi CR, Pilati P, Nitti D, Marincola FM: Quantitative real-time PCR: a powerful ally in cancer research. Trends $\mathrm{Mol}$ Med 2003, 9:189-195.

13. Petricoin EF 3rd, Hackett JL, Lesko LJ, Puri RK, Gutman SI, Chumakov K, Woodcock J, Feigal DW Jr, Zoon KC, Sistare FD: Medical applications of microarray technologies: a regulatory science perspective. Nat Genet 2002, 32:474-479.

14. Rockett JC, Hellmann GM: Confirming microarray data - is it really necessary? Genomics 2004, 83:54I-549.

15. Klein D: Quantification using real-time PCR technology: applications and limitations. Trends Mol Med 2002, 8:257-260.

16. Yuen T, Wurmbach E, Pfeffer RL, Ebersole BJ, Sealfon SC: Accuracy and calibration of commercial oligonucleotide and custom cDNA microarrays. Nucl Acids Res 2002, 30:e48.

17. Czechowski T, Bri RP, Stitt M, Scheible W, Udvardi MK: Real-time RT-PCR profiling of over I400 Arabidopsis transcription factors: unprecedented sensitivity reveals novel root- and shoot-specific genes. Plant J 2004, 38:366-379.

18. Affymetrix technical note: Performance and validation of the GeneChip human genome set. [http://www.affymetrix.com/sup port/technical/technotesmain.aff $\mathrm{x}]$.

19. Mutch DM, Berger A, Mansourian R, Rytz A, Roberts MA: The limit fold change model: a practical approach for selecting differentially expressed genes from microarray data. $B M C$ Bioinformatics 2002, 3:17.

20. Etienne W, Meyer MH, Peppers J, Meyer RA Jr: Comparison of mRNA gene expression by RT-PCR and DNA microarray. Biotechniques 2004, 36:618-620. 622, 624-616

21. Gilbertson RJ, Clifford SC: PDGFRB is overexpressed in metastatic medulloblastoma. Nat Genet 2003, 35:197-198.

22. Kees UR, Carter TL, Watt PM, Kumar R, Baker DL, Reaman GH, Sather HN, Burton PR: p I 6INK4A gene deletion in pediatric acute lymphoblastic leukemia. Blood 200 I, 97:4003-4004.

23. Hoffmann K, Firth MJ, Freitas JR, de Klerk NH, Kees UR: Gene expression levels in small specimens from patients detected using oligonucleotide arrays. Mol Biotech 2005, 2 I:3 I-38.

24. Liu G, Loraine AE, Shigeta R, Cline M, Cheng J, Valmeekam V, Sun S, Kulp D, Siani-Rose MA: NetAffx: Affymetrix probesets and annotations. Nucl Acids Res 2003, 31:82-86. 
25. Kees UR, Heerema NA, Kumar R, Watt PM, Baker DL, La MK, Uckun FM, Sather HN: Expression of HOXII in childhood T-lineage acute lymphoblastic leukaemia can occur in the absence of cytogenetic aberration of I0q24: a study from the Children's Cancer Group (CCG). Leukemia 2003, 17:887-89.

Publish with Bio Med Central and every scientist can read your work free of charge

"BioMed Central will be the most significant development for disseminating the results of biomedical research in our lifetime. " Sir Paul Nurse, Cancer Research UK

Your research papers will be:

- available free of charge to the entire biomedical community

- peer reviewed and published immediately upon acceptance

- cited in PubMed and archived on PubMed Central

- yours - you keep the copyright

Submit your manuscript here:

http://www.biomedcentral.com/info/publishing_adv.asp
BioMedcentral 